\title{
Distinguishing brain oscillations - understanding differences in topography, frequency, and incidence by a simple modeling framework Eckehard Olbrich ${ }^{* 1,2}$ and Thomas Wennekers ${ }^{1,2}$
}

\author{
Address: ${ }^{1}$ Max Planck Institute for Mathematics in the Sciences, D-04103, Leipzig, Germany and ${ }^{2}$ Centre for Theoretical and Computational \\ Neuroscience, University of Plymouth, PL4 8AA, Plymouth, UK \\ Email: Eckehard Olbrich* - olbrich@mis.mpg.de \\ * Corresponding author
}

from Eighteenth Annual Computational Neuroscience Meeting: CNS*2009

Berlin, Germany. 18-23 July 2009

Published: I 3 July 2009

BMC Neuroscience 2009, I0(SuppI I):P229 doi:I0.II86/I47I-2202-I0-SI-P229

This abstract is available from: http://www.biomedcentral.com//47I-2202/I0/SI/P229

(c) 2009 Olbrich and Wennekers; licensee BioMed Central Ltd.

Brain oscillations such as alpha waves in relaxed wakefulness, sleep spindles and slow oscillations in sleep, or beta and gamma oscillations are important markers for the brain state and may also play functional roles in some cognitive processes. The different names indicate that they are considered as distinct entities, with frequency and topography being the features that distinguish the two. Sleep spindles in the human EEG, for instance, are oscillations in a frequency range between 11 and $16 \mathrm{~Hz}$. They were shown to be related to the memory consolidating effects of sleep [1]. One often distinguishes between slow and fast spindles, which supposedly serve different functional purposes. Both types of spindles have not only different frequencies, but also different topographical distributions in the scalp EEG. The distinction between slow and fast sleep spindles in measured data is, however, by no means simple and uncontroversial. This is primarily due to the large amount of variation in the frequency of spindles, which not only vary across individuals but are also state-dependent (sleep stage and time in the night) [2]. Additionally, the delineation to other types of oscillations can be unclear - for instance between slow sleep spindles and frontal alpha oscillations. Similar problems occur for other brain oscillations, for instance in the analysis of delta and slow oscillations.

This situation poses a challenge to both data analysis and computational modeling. The present work continues our previous work [3] on combining data-analysis methods with computational modeling to improve the understanding of brain oscillations.

Our basic model is a two-dimensional noisy field of excitatory-inhibitory neural oscillators similar to the WilsonCowan equations but coupled over an adjustable lateral region. An additional oscillator can be coupled to the network either locally or globally mimicking thalamic driving. Artificial "EEG" signals are then produced as local averages of neural activity and oscillatory events are analysed using both a recently developed method based on fitting linear models to short segments in a sliding window fashion [2] and spectral analysis. The model is augmented by an additional slow hysteresis loop that can switch the local circuits between two operational states thus mimicking the cortical slow oscillation between up and down states. Systematic parameter inhomogeneities (gradients, blocks, random values) modulate the properties of local elements further.

We demonstrate that this model reveals oscillatory patterns at multiple frequencies beyond the single frequency mean field solution. Properties of the observed oscillations are investigated as functions of the model parameters. We discuss to which extent these findings reveal limitations on the view of brain oscillations as discrete 
physiological and functional entities, and consider possible implications.

\section{References}

I. Born J, Rasch B, Gais S: Sleep to remember. Neuroscientist 2006:410-424.

2. Olbrich E, Achermann P: Analysis of oscillatory patterns in the human sleep EEG using a novel detection algorithm. J Sleep Res 2005, 14:337-346.

3. Olbrich E, Wennekers T: Dynamics of parameters of neurophysiological models from phenomenological EEG modelling. Neurocomputing 2007, 70:1848-1852.

Publish with Bio Med Central and every scientist can read your work free of charge

"BioMed Central will be the most significant development for disseminating the results of biomedical research in our lifetime. " Sir Paul Nurse, Cancer Research UK

Your research papers will be:

- available free of charge to the entire biomedical community

- peer reviewed and published immediately upon acceptance

- cited in PubMed and archived on PubMed Central

- yours - you keep the copyright 